\title{
NEW PERSPECTIVE IN THE DESIGN OF QUALITY MANAGEMENT SYSTEMS
}

José G. Vargas-Hernández University Center for Economic and Managerial Sciences, University of Guadalajara, Mexico E-mail: jvargas2006@gmail.com, jjosevargas@cucea.udg.mx

Patricia Calderón Campos Instituto Tecnológico de Lázaro Cárdenas, Mexico E-mail: patriciatecmx@gmail.com

Felipe Palomares Salceda Instituto Tecnológico de Lázaro Cárdenas, Mexico E-mail: fpalomares@yahoo.mx

Rebeca Almanza Jiménez Instituto Tecnológico de Lázaro Cárdenas, Mexico E-mail: patriciatecmx@gmail.com

Submission: $24 / 01 / 2017$

Revision: 17/02/2017 Accept: 20/02/2017

\section{ABSTRACT}

This article aims to analyze the different trends and models of the current quality management systems, identifying areas of opportunity in these to establish proposals for care that give rise to a new management system, flexible, efficient and effective Supported by a system of sociotechnical work. The competitive climate in today's business has multiplied significantly in the face of the dynamics of change and the presence of ever shorter business cycles. It is a fact that in the last decades the market has been acquiring an increasing dynamism. Today, companies are developing in a more competitive national and international economy, with increasing demands for productivity, where market laws force them to deepen and change strategies and policies, to plan, create and innovate, to have a high degree of resilience and Sensitivity to anticipate future needs and to be able to survive and develop in a complex and increasingly competitive environment. 
INDEPENDENT JOURNAL OF MANAGEMENT \& PRODUCTION (IJM\&P)

http://www.ijmp.jor.br

v. 8, n. 3, July - September 2017

ISSN: 2236-269X

DOI: 10.14807/ijmp.v8i3.620

In these times the markets are increasingly informed, so their expectations are increasingly demanding, for this reason is that quality becomes a differentiating element and at the same time the key factor of a company's lasting success.

Keywords: Quality, design, management systems.

\section{INTRODUCTION}

The concept of quality and its different approaches have evolved from what was the quality inspection (reaction), until what today is called Total Quality Management (excellence). Two major trends in Quality Management coexist in today's environment. The first trend has to do with adopting a standardization approach and designing a quality system based on standards, such as those of the ISO 9000 series. The second trend has to do with an increasingly used approach that is the consideration of some of the models that underlie the quality awards as a basis for quality management.

Both tendencies with their approaches and models present gaps that cause problems of functionality in the organizations that operate them without being able to reach the expected results. To fill the gaps detected in these trends and with the firm conviction of improving the efficiency and effectiveness of the management systems, specific proposals are established regarding the identification, establishment, operation and measurement of the processes that integrate them. On the other hand, it establishes the need for quality management systems to focus on the imperative need to generate and bring to the highest levels motivation and job satisfaction in the understanding that sustained attractiveness is only achieved with motivated and satisfied workers.

Finally, it is necessary to design or redesign the work system that supports the management system according to the nature of the company as to whether it is new or is in operation. For the design or redesign, the fundamentals and principles on which the model must be built are established, considering also for this purpose a socio-technical approach, for the evidence that exists regarding the approach that helps organizations to create new structures, workflows and environments that are collaborative, integrated and capable of handling rapid technological changes.

A final consideration is mentioned when establishing that in order to design and implement a work system of this type, a new conception around the work is 
necessary, as well as the way in which the contents and the tasks to be carried out in the work are described.

\section{QUALITY}

When speaking of quality, this word is incorporated in human language as a symbol of excellence; it is what allows a person, a product or a service to be well recommended. It has become a philosophy of life and is reflected in our family, academic, work and commercial environment. The word quality has multiple meanings (JURAN; GRYNA, 1993). Therefore, it can be stated that quality is the set of characteristics of products that satisfy the needs of customers and, therefore, make the product satisfactory; "Degree of fulfillment of requirements" for this reason is valued in percentage.

For Jablonsky (1995), Quality is a cooperative way of operating companies, which is based on the talents and abilities of both the worker and the management to continuously improve quality and productivity, using work teams. It also mentions these principles: User's point of view, attention in the process, as well as in results, prevention versus inspection, mobilizing knowledge of the workforce, fact-based decision making, and feedback.

\subsection{Dimensions of quality}

It is important, at the beginning of the quality process, to determine in which dimensions of quality, the quality assurance effort will take place. It is referred to the following dimensions:

\section{a) Professional competence}

It refers to the capacity and performance of the group functions of the organization. That is, if people have the capacity and the knowledge necessary to carry out the tasks. It involves the administrative, technical and support staff. To overcome technical procedures that is involved.

\subsection{Customer satisfaction (user)}

It refers to the relationships between suppliers and customers. These relationships are those that produce trust, credibility, and are demonstrated through respect, confidentiality, courtesy, understanding. Also, listening and communicating are important. 


\subsection{Efficiency}

When services are efficient they are said to provide more optimal care to the user and the community. That is, they provide the greatest benefit within the resources with which it is counted. Two ways of improving quality in this dimension are presented. This is to eliminate waste and avoid mistakes while reducing costs.

\subsection{Continuity}

Services must be offered consistently and with the same quality.

\subsection{Security}

It involves reducing risks through the establishment of safe processes.

\subsection{Contort}

They increase customer satisfaction and its desire to return to the organization to receive care in the future. The comforts are also important because they can influence the expectations that the user has and the confidence that he feels in relation to other aspects of the service or product. They are often related to the physical aspect of the organization, staff and materials, as well as with the physical comforts, cleanliness and privacy.

The quality in the companies begins with the training of the personnel in the knowledge and management of the norms, followed by the creation of control points, from the reception of the materials to the after-sales service. These controls produce results that are analyzed by the directives to make decisions or implement corrective actions.

Some of its advantages are:

a) It improves the production time in the companies.

b) Keep materials and supplies in good condition.

c) Reduce production costs.

d) It increases the possibility of negotiation.

e) It guarantees the positioning of the product in the markets.

f) Increase the profitability of the company.

According to the environment in which the organizations move, the quality in the products and the services has become a fundamental factor for the success of 
INDEPENDENT JOURNAL OF MANAGEMENT \& PRODUCTION (IJM\&P)

http://www.ijmp.jor.br

V. 8, n. 3, July - September 2017

ISSN: 2236-269X

DOI: 10.14807/ijmp.v8i3.620

the modern organizations. Organizations create a product or service for the purpose of meeting the needs or requirements of customers. These requirements have to be operationalized and transformed into technical specifications. The demand by the customers towards the fulfillment of the requirements that must satisfy the products and the services is every day greater at world-wide level. To meet this demand, and also to obtain economic returns, it is necessary to improve quality in a systematic way.

\section{Quality and current management systems}

Quality is a constant in today's language. Everyone accepts that if does not work with quality the organization is in danger. In ever more competitive markets, quality becomes a differentiating element capable of generating sustainable competitive advantages in companies. If quality is the main requirement for a company's long-term success, it seems appropriate to consider how it is achieved (CELA, 1996).

Given the dynamic nature of today's markets, it is clear that quality requires an attitude of permanent innovation. Drucker (1955) argues about innovation considering that it is not spontaneous but is born of "real work", that is, of daily work. For Kim and Mauborgne (2005), value innovation is the simultaneous pursuit of radically superior value for customers, and cost reduction. It means making customers' lives much simpler, more productive, more comfortable, and more fun, with fewer risks and all respecting the environment.

Today, management models must lead organizations according to their nature to deliver attractive quality that is as close as possible to meet or exceed customer expectations. By the market movement itself, what today is attractive tomorrow may not be, so its maintenance is based on the search for technological innovations, products and services.

The concept of quality and the different approaches that started in quality inspection (reaction), up to what is now known as Total Quality Management (excellence) have evolved towards an increasingly global vision, so it has become a strategic factor (DALE, 1994). Faced with this reality, the fundamental question that arises is to analyze how this importance of quality in business practice translates. 
INDEPENDENT JOURNAL OF MANAGEMENT \& PRODUCTION (IJM\&P)

http://www.ijmp.jor.br

V. 8, n. 3, July - September 2017

ISSN: 2236-269X

DOI: 10.14807/ijmp.v8i3.620

The generation of quality and quality improvement do not arise spontaneously, but of a structure of activities in the organization in order to achieve this goal. This set of activities is what is called Quality Management. A quality management system is a set of mutually related or interacting elements to direct and control an organization with respect to quality (ISO-9000: 2005, 2007).

In the current environment, two major trends in Quality Management coexist, which provide two different models. Each model is an instrument that helps organizations to establish a management system based on total quality (CLAVER; TARÍ, 1999). The first trend has to do with adopting a standardization approach and designing a quality system based on standards, such as the ISO 9000 series.

The second trend has to do with an increasingly approach, each time more used, it is the consideration of some of the models that underlie quality awards as the basis for quality management (CLAVER; TARÍ, 1999). A common factor that forms part of the essence of each of these approaches is to encourage total quality management, as a method of obtaining competitive advantages, with a customer orientation.

Today, standardized management systems and, to a lesser extent, nonstandardized but not exempt systems have been seen as generating excessive bureaucracy. With excessive regulations, methodologies and bureaucratic controls, only the innovative initiative is frozen, curtailing actions. These management systems come to have a sense of "straitjackets" for employees and the system of work on which they are built scarcely generates workers with a high sense of motivation and job satisfaction.

Central to quality management systems is analyzing processes with a systemic approach and vision. An organization will be as efficient or inefficient as its processes and it is here that lays the key to the quality, productivity and competitiveness of companies. Due to the impact and importance of the processes in a management system and in the work system that supports it, it is necessary that they be "sanitized" in order to achieve the goals and objectives set, in such a way that they are constituted by two types of main activities which are those that bring value to the client and those that add value to the organization. "Parasitic" activities must be eliminated. This speaks of process innovation. 
INDEPENDENT JOURNAL OF MANAGEMENT \& PRODUCTION (IJM\&P)

http://www.ijmp.jor.br

V. 8, n. 3, July - September 2017

ISSN: 2236-269X

DOI: 10.14807/ijmp.v8i3.620

Another key factor in current management systems is the measurement of processes, in order to determine their efficiency, effectiveness and performance. The current measurements used in the business field to measure efficiency and effectiveness, practically lack value without being compared.

For Perez (2004), it is necessary to leave aside the measurements that imply current performance against the past and current performance against their counterparts, to focus on a current performance measurement system against the best at the international level. As much as possible replace the indicators in percent, to work and adopt the indicators in number of times.

The efficient and effective operation of the processes to achieve the required level of performance depends on the competence and the necessary skills of the personnel who operate them. So it is necessary to provide training and training not in the traditional way, which it is diverted from the process, without monitoring, measuring and evaluating its impact on productivity, but preparing them to achieve the desired levels of productivity. The training should be evaluated by productivity in the company. In this regard (PÉREZ, 2004), state that the training must be mounted on the process of transformation, in the closest field of work without closing the cycle until verifying that the person has learned

\section{QUALITY, SATISFACTION AND WORK MOTIVATION}

At present the experience shows that attractive quality and competitive value advantage with innovation, it is only possible to generate it with motivated and satisfied workers. The competitive advantage is achieved from the dual orientation: consumer satisfaction and the development of people (PÉREZ, 2004).

Given this reality, it is undeniable that management models and systems develop activities that generate true motivation and job satisfaction. To continue to satisfy consumers, the organization must continually respond to changes in market demand through a flexible working system. In a world of rapidly changing markets, flexibility is the key to effective organizational design. That is, the company must be a company with a high degree of resilience.

An orientation towards people's development can provide the flexibility to respond continuously to changes in the market. According to Pérez (2004), 
INDEPENDENT JOURNAL OF MANAGEMENT \& PRODUCTION (IJM\&P)

http://www.ijmp.jor.br

v. 8, n. 3, July - September 2017

ISSN: 2236-269X

DOI: 10.14807/ijmp.v8i3.620

subjective measures should be dispensed with for job satisfaction. Instead, job satisfaction should be measured in terms of productivity.

With regard to labor motivation, Hackman and Oldham (1980) establish that there are three psychological states experienced by a person that in his work generate motivation and job satisfaction. These states have to do with (1) experiences of the significance of the activity. The individual must perceive that his work is worth or is important through a system of values that he accepts, 2) responsibility experiences: He must believe that he personally is responsible for the results of his own efforts and 3) knowledge of the results: He must be able to determine on an acceptably regular basis if the results of his work is or is not satisfactory.

When these three conditions are present, the person tends to feel very good about him if he acts well. Then the internal motivation for work, satisfaction and quality of work are high and absenteeism and fluctuation are low. According to Hackman and Oldham (1980), there are five "essential" features of work that attract these previously described psychological states. These five core dimensions have a high potential to motivate people to do their jobs.

Three of the five essential dimensions contribute to giving significance to work for the worker.

a) Variety of skills: Degree in which an employment requires the worker to develop activities that retain his skills and ingenuity,

b) Identification of the task: Degree in which the work requires to be understood as a finished and identifiable piece of the same work, doing the work from the beginning to the end with a visible result,

c) Task significance: The degree to which work has a substantial and perceptible impact on the lives of other people, both in the immediate organization and in the world at large (Hackman and Oldham, 1980). A fourth central dimension, continues the author, leads the worker to experience a high responsibility in his work, this is:

d) Autonomy: The degree to which work gives the worker freedom, independence and discretion in the scheduling of work and the determination of how to carry it out. The fifth and last essential dimension is: 
e) Feedback: This is the degree to which a worker carrying out the work activities required by his position obtains information about the effectiveness of his efforts.

While it is true that quality can be a trigger in the success of an organization, it is also convenient to consider that what makes a company win in the market is not quality, but what generates it. Quality is generated through an organizational change of depth, that is, quality is a consequence of an organizational change and organizational change begins with the redesign of systems and therefore of work systems.

For Pérez (2004) redesigning requires the restructuring of the work system and restructuring must be done in such a way that man can bring his full potential and honor him as an individual. The system of work designed and implemented is solely responsible for the problems that exist in an organization and the behavior of people, as it represents the basis of the organizational culture.

Due to the above, the design or, if applicable, the redesign of the current work system, should be aimed at developing cultures with competitive advantages, with a high resilient sense and characterized by high performance and high commitment. One approach capable of giving birth to this type of work is the socio-technical approach. The reason for leaning on this approach is based on the fact that it has led the major transformations that are being experienced in the developed world over the past 20 years.

By leaning towards the design of a work system with a socio-technical approach, it is necessary to specify some fundamentals under which the system must be constructed. These fundamentals are: a) the design or redesign depending on the case, is facilitated leaving these in the hands of the workers (as long as there is retribution). The reason is that when staff designs its own systems of work, it becomes the protagonist of its own destiny. b) The work designs must be constructed considering the 5 dimensions mentioned by Hackman and Oldham (1980).

With regard to the design of work systems with competitive advantages, Sherwood (1985) considers that organizations that want to improve productivity and quality of life in the workplace need to know how the work system itself is designed 
INDEPENDENT JOURNAL OF MANAGEMENT \& PRODUCTION (IJM\&P)

http://www.ijmp.jor.br

V. 8, n. 3, July - September 2017

ISSN: 2236-269X

DOI: 10.14807/ijmp.v8i3.620

and how people are organized to fulfill their tasks. This author states that there are two fundamental questions to achieve the above, these are: The design of the work itself and the structure of the work organizations. These issues, when considered, create planned and successful work cultures with competitive advantages, cultures characterized by energy learning and quality.

The designs and redesigns must be realized where the majority can develop. It is necessary first to eliminate the problems in order to design or redesign a work system with a socio-technical approach. Sherwood (1995) argues that in order to implement this form of society, management must change its ways of thinking mainly in three areas: In its way of seeing people, its way of seeing work, and its way of seeing the role of management. As for the people, a notion that must be abandoned is that there are two kinds of people in the world of work: leaders and workers. As for work, look at primary resources in the design of work to those who are closest to the work, the people who are doing the work now and will do so in the future.

Finally the Role of management, in this aspect, leaders need every day to be flexible enough to change in order to meet the needs that are developed in the new system of work. Leaders should focus their attention on the outside instead of inward, that is, they should look outside the work process instead of addressing the internal demands of the work. The role of management changes to supporting culture rather than controlling the workforce

\section{THE SOCIO-TECHNICAL WORK SYSTEM}

The socio-technical approach helps organizations to create new structures, workflows, and environments that are collaborative, integrated, and able to handle rapid technological change (DOYLE, 1989). In the design of the socio-technical work system, it is necessary to guarantee the optimization of the three components: Social, technical and environment (PÉREZ; GALIS, 2002).

In this way, the optimization of the complete system is achieved. Deepening the social system and considering the proposal put forward by Pérez and Galis (2002), some important principles of the socio-technical approach that must be taken into account for the design of work systems are: 
a) Consider work processes as open systems, in permanent interaction with the environment, not only general and broader, the external, but also with the immediate, the internal.

b) Use few levels of hierarchy and many levels of equality.

c) View the organization as workflow and not as a complex of hierarchical levels.

d) The work should be designed in such a way that there are minimal interfaces.

e) A system of gates.

The socio-technical system, Pérez and Galis (2002) continue to argue, should be designed in such a way that when an error occurs, the gates are closed immediately, thus preventing the error from continuing through the flow.

a) The self-design. A basic premise of the socio-technical approach is that the organization's new designs cannot be imposed by external agents. The ideal people to design a flow are the workers themselves.

b) Indicate for the design of work systems only the minimum critical specifications.

c) Continuous redesign.

d) The feedback. Feedback is information about the differences between desired outcomes and actual outcomes, which is used to improve performance. The feedback in this sense must be frequent, close to the facts and with positive reinforcement.

e) Consider everyone as customers. In order to design and implement a work system of this type, a new conception around work is needed, as well as the way in which the contents and tasks to be performed in a job are described. Today it is thought that the work should not be described, but the result expected of it.

\section{CONCLUSIONS}

At present the markets are increasingly informed, so their expectations are becoming more demanding, giving rise in the business environment to increasingly competitive environments, that is why quality becomes a differentiating element and at the same time in the key factor of a company's lasting success. Quality, even when it has been defined and conceptualized from different angles and perspectives, 
is finally defined by the client himself who defines it from a perspective of comparison.

Hence, if the concept has a comparative nature, quality requires an attitude of permanent innovation. Innovation must take place in the daily work done by an organization. The result of this should be the generation and delivery of an attractive quality with radically superior value for the clients that imply making the life of the clients much simpler, more productive, more comfortable, and more fun, with fewer risks.

To achieve this, it implies establishing a management system with a systemic vision and thinking and a new perspective on the identification, design, measurement and operation of processes. This new perspective must consider the reorganization and conformation of the processes by activities that generate value for both the client and the organization avoiding the parasitic activities.

On the other hand the measurement of these, should focus on a system of measurement of current performance against the best at the international level and to the extent possible replace the indicators in percent, to work and adopt indicators in number of times, contrary one can fall into a conformism. In order for processes to be operated efficiently and effectively and to achieve established goals and objectives, it is imperative to prepare people to achieve desired levels of productivity through continuous training, which must be built on the process of processing, tracking, measuring and evaluating their impact on productivity.

Taking into consideration that quality becomes a differentiating element capable of generating sustainable competitive advantages in companies, it is inescapable to have the full conviction that the delivery of an attractive quality and the development of a competitive value advantage with innovation are only possible with motivated and satisfied workers. Labor satisfaction, rather than being measured by subjective means, must be measured in terms of productivity. When productivity levels are at least desired, it becomes apparent that people are motivated and satisfied.

Motivation and job satisfaction is something that must be achieved through the design of a system of work that considers the five dimensions proposed by Hackman and Oldham (1980) in order that the work can achieve that the worker 
INDEPENDENT JOURNAL OF MANAGEMENT \& PRODUCTION (IJM\&P)

http://www.ijmp.jor.br

V. 8, n. 3, July - September 2017

ISSN: 2236-269X

DOI: 10.14807/ijmp.v8i3.620

experiences the three psychological states factors that make internal motivation for work, satisfaction and quality of work high and low absenteeism and fluctuation.

The design of this system of work and its implementation should generate a sense of belonging on the part of the worker and this must be generated through their involvement in the design of their own work, as these are the closest to it. In addition to which are the people who are doing the work now and will do it in the future. With respect to the leadership exercised by the organization, it is necessary to change its perspective regarding the way of thinking about the people, the work and the role of management. When this is done, the role of leadership changes to support culture rather than controlling the workforce.

Finally, being aware that quality is a consequence of an organizational change, which begins with the redesign of systems and these redesigns in turn requires the restructuring of the work system, the new work system product either design or redesign, must be such as to help organizations create new structures, workflows, and environments that are collaborative, integrated, and capable of handling rapid technological change.

It is for this reason that the system of work must be designed under the sociotechnical approach and the principles that govern it, same that have been described previously. In order to design and implement a work system of this type, a new conception around work is necessary, as well as the way in which the contents and the tasks to be performed in a job are described.

\section{REFERENCES}

CELA, L. (1996) Calidad. Qué es. Cómo hacerla, Gestión 2000: Barcelona.

CLAVER, J.; TARÍ, J. (1999) Calidad y Dirección de Empresas. Madrid: Ed Cívitas.

DALE, G. (Ed.) (1994) Managing Quality. London: Prentice Hall.

DOYLE, M. (1989) Creando grandes cambios organizacionales. Traducción de Oscar Torres de la luz. La habana: CETED U.H.

DRUCKER, P. (1995) Managing in turbulent times. New York: Harper and Row Publisher.

HACKMAN, R.; OLDHAM G. (1980) Work Redesing. San Francisco: AdissonWesley Pubs.

JABLONSKY, J. R. (1995) TQM: Como implantarlo. Aprenda a administrar la calidad total, México. CECSA. 
JURAN; GRYNA (1993) Manual de Control de Calidad, v. 1, Madrid, McWrag-Hill. KIM, C.; MAUBORGNE, R. (2005) Blue Ocean Strategy. Boston: HBS Press PÉREZ, J. (2004) Competencia Organizacional. Morelia: Contreras Impresores. PÉREZ, J.; GALIS, A. (2002) El Enfoque Sociotécnico Sistemas de alto rendimiento-alto compromiso. Morelia.

SHERWOOD, J. (1995) Creando culturas de trabajo con ventajas competitivas. Cambridge: MIT 